УДК 676.1.054.1

\title{
ПОИСК ОПТИМАЛЬНЫХ ТЕХНОЛОГИЧЕСКИХ РЕЖИМОВ В ПРОИЗВОДСТВЕ ТРУДНОВОСПЛАМЕНЯЕМЫХ ДРЕВЕСНОВОЛОКНИСТЫХ ПЛИТ
}

\author{
(C) А.В. Антонов ${ }^{1 *}$, Н.А. Петрушева ${ }^{2}$ Н.Д. Алашкевич ${ }^{1,3}$, Н.С. Решетова ${ }^{3}$ \\ ${ }^{1}$ Сибирская пожарно-спасательная академия ГПС МЧС России, \\ ул. Северная, 1, Железногорск, Красноярский край, 662972 (Россия), \\ e-mail: antonov012@mail.ru \\ ${ }^{2}$ Лесосибирский фрилиал Сибирского государственного технологического \\ университета, ул. Победы, 29, Лесосибирск, 662543 (Россия) \\ ${ }^{3}$ Сибирский государственный технологический университет, пр. Мира, 82, \\ Красноярск, 660049 (Россия)
}

В работе представлены результаты решения задачи поиска оптимальных режимов процесса размола в производстве трудновоспламеняемых древесноволокнистых плит с целью минимизации расхода электроэнергии. Регрессионные модели второго порядка, полученные в результате реализации многофакторных экспериментальных исследований, представленные и описанные в ранее опубликованных работах, дают богатую информацию о влиянии варьируемых факторов на выходные величины. Эти модели можно использовать для оптимизации условий функционирования объекта. Эффективным методом отыскания оптимальных условий функционирования объекта по уравнению регрессии второго порядка является метод квази-Ньютона. Задача по определению оптимальных условий проведения процесса размола при производстве трудновоспламеняемых древесноволокнистых плит мокрым способом для размола щепы была решена в два этапа. На первом этапе была установлена зависимость удельного расхода электроэнергии от технологических и конструктивных факторов процесса размола в производстве трудновоспламеняемых ДВП. На втором этапе были определены такие технологические характеристики процесса размола древесноволокнистой массы и конструктивные параметры размалывающих машин, для которых значение удельного расхода электроэнергии оказалось минимальным. Решение поставленной задачи позволит, варьируя конструктивными параметрами размалывающих машин и технологическими характеристиками процесса размола древесноволокнистой массы, не только получить древесноволокнистые плиты с заданными свойствами, но и сократить расход электроэнергии на производство в среднем на 7\%. Экономический эффект от применения оптимальных режимов размола равен экономии условно-постоянной части расходов в себестоимости за счет снижения удельного расхода электроэнергии и затрат на сырье, прибыли предприятия за счет улучшения качества готовых древесноволокнистых плит.

Ключевые слова: древесноволокнистая плита, пожарная опасность, математическое описание, функционирование объекта, оптимальные условия.

\footnotetext{
Антонов Александр Викторович - начальник отдела прикладных исследований и инновационных технологий, кандидат технических наук, e-mail: antonov012@mail.ru

Петрушева Надежда Александровна - доцент кафедры технологии лесозаготовительных и деревоперерабатывающих производств, e-mail: info@lfsibgtu.ru

Алашкевич Юрий Давыдович - заведующий кафедрой машин и аппаратов промышленных технологий, доктор технических наук, профессор, e-mail: mapt@sibgtu.ru Решетова Наталья Сергеевна - доцент кафедры машин и аппаратов промышленных технологий, e-mail:mapt@sibgtu.ru
}

\section{Введение}

В связи с возрастающим спросом на древесноволокнистые плиты наблюдается рост требований и к их физико-механическим показателям, которые определяют дальнейшие возможности их использования в различных отраслях промышленности. Это обстоятельство, несомненно, требует проведения научных исследований в этом направлении для получения высококачественной продукции.

В результате проведенных в лаборатории лесоперерабатывающей, целлюлозно-бумажной и хи-

\footnotetext{
* Автор, с которым следует вести переписку.
} 
мической технологии древесины Лесосибирского филиала СибГТУ экспериментальных исследований были установлены зависимости параметров горючести готовой древесноволокнистой плиты от зернового состава и массовой доли вспученного вермикулита $[1,2]$ и разработаны математические модели, адекватно описывающие процесс получения древесноволокнистых полуфабрикатов в производстве трудновоспламеняемых древесноволокнистых плит [3,4]. Регрессионные модели второго порядка, полученные в результате реализации многофакторных экспериментальных исследований, представленные и описанные в работах [1-5], дают богатую информацию о влиянии варьируемых факторов на выходные величины. Эти модели можно использовать для оптимизации условий функционирования объекта [6]. Имеется в виду отыскание таких значений варьируемых факторов в интервалах их варьирования, для которых значение выходной величины оказывается максимальным или минимальным [7].

Эффективным методом отыскания оптимальных условий функционирования объекта по уравнению регрессии второго порядка является метод квази-Ньютона [8]. Суть метода заключается в том, что на каждом шаге вычисляют значения функции в различных точках для оценивания первой и второй производной, и эти данные используются для определения направления изменения параметров и минимизации функции потерь. Далее производится отыскание оптимальных значений варьируемых факторов, при которых функция отклика достигает своего максимума или минимума в зависимости от поставленной задачи [9].

Таким образом, на основании результатов проведенных экспериментальных исследований необходимо решить задачу поиска оптимальных условий проведения процесса размола при производстве трудновоспламеняемых древесноволокнистых плит мокрым способом с минимизацией затрат на электроэнергию.

\section{Экспериментальная часть}

В ранее опубликованных работах [3-5] была установлена зависимость физико-механических свойств готовой продукции от технологических и конструктивных параметров процесса размола и массовой доли вспученного вермикулита в композиции.

Исследования по размолу древесноволокнистых полуфабрикатов осуществлялись на промышленных установках завода ДВП ОАО «Лесосибирский ЛДК №1», а также на экспериментальных и полупромышленных установках лаборатории лесоперерабатывающей, целлюлозно-бумажной и химической технологии древесины Лесосибирского филиала СибГТУ.

В качестве исходного сырья для получения древесноволокнистой массы использовались исключительно древесные отходы лесопильного производства и низкокачественная древесина со склада сырья, по-

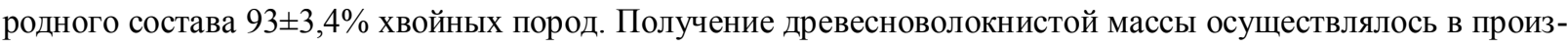
водственных условиях в две ступени: I ступень - размол технологической щепы в дефибраторе до степени помола 11-14 ДС; ІІ ступень - размол древесноволокнистой массы в рафинаторе до степени 18-22 ДС.

Для придания древесноволокнистым плитам специальных свойств в качестве наполнителя применяли вспученный вермикулит $[10,11]$. В наших исследованиях был использован вспученный вермикулит по

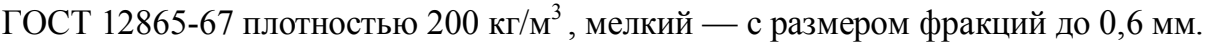

Размерные и физико-механические характеристики готовой плиты (толщина, предел прочности при статическом изгибе, водопоглощение) определялись по ГОСТ 19592-80 «Плиты древесноволокнистые. Методы испытаний».

Построение математических моделей объектов не являлось конечной целью наших исследований. Модель служит средством для получения информации о поведении объекта, управления им, прогнозирования его состояния, а также является основой для отыскания оптимальных условий функционирования объекта [7].

Известно, что в производстве древесноволокнистых плит предварительная подготовка полуфабриката потребляет до 65\% всех затрат электроэнергии производства [9]. И, поскольку в качестве целевой функции в оптимизационных задачах необходимо выбирать величину, связанную с экономичностью работы рассматриваемого объекта и количественной оценкой оптимизируемого качества объекта, в данной работе целесообразно выбрать в качестве целевой функции удельный расход электроэнергии процесса размола.

Таким образом, задача по определению оптимальных условий проведения процесса размола при производстве трудновоспламеняемых древесноволокнистых плит мокрым способом для размола щепы была решена в два этапа. На первом этапе была установлена зависимость удельного расхода электроэнергии от технологических и конструктивных факторов процесса размола в производстве трудновоспламеняемых ДВП.

Общая схема математического и статистического анализа данного процесса описана в [7]. Уровни и интервалы варьирования управляемых факторов приведены в таблице. 
Уровни и интервалы варьирования факторов

\begin{tabular}{|c|c|c|c|c|}
\hline \multirow{2}{*}{$\begin{array}{c}\text { Наименование } \\
\text { фактора }\end{array}$} & \multicolumn{3}{|c|}{ Уровни фактора } & \multirow{2}{*}{$\begin{array}{c}\text { Интервал } \\
\text { варьирова- } \\
\text { ния }\end{array}$} \\
\hline & верхний & нижний & основной & \\
\hline \multicolumn{5}{|c|}{ І ступень размола (дефибратор) } \\
\hline Износ сегментов $L / h\left(X_{l}\right)$ & 10 & 2 & 6 & 4 \\
\hline Зазор между дисками $z$, мм $\left(X_{2}\right)$ & 0,15 & 0,05 & 0,1 & 0,05 \\
\hline Скорость вращения нижнего шнека $n$, об/мин $\left(X_{3}\right)$ & 15,4 & 12 & 13,7 & 1,7 \\
\hline Массовая доля вспученного вермикулита $\omega_{6}, \%$ к а.с.в. $\left(X_{4}\right)$ & 50 & 10 & 30 & 20 \\
\hline \multicolumn{5}{|c|}{ II ступень размола (рафинатор) } \\
\hline Износ сегментов $L / h\left(X_{l}\right)$ & 10 & 2 & 6 & 4 \\
\hline Зазор между дисками $z$, мм $\left(X_{2}\right)$ & 0,15 & 0,05 & 0,1 & 0,05 \\
\hline Концентрация древесноволокнистой массы $c, \%\left(X_{3}\right)$ & 3,5 & 2,5 & 3 & 0,5 \\
\hline Массовая доля вспученного вермикулита $\omega_{6}, \%$ к а.с.в. $\left(X_{4}\right)$ & 50 & 10 & 30 & 20 \\
\hline
\end{tabular}

К неконтролируемым факторам эксперимента относились не указанные выше геометрические и физико-механические характеристики процесса.

В результате статистической обработки полученных экспериментальных данных были получены следующие уравнения регрессии:

- для первой ступени размола

$$
Y_{6}^{\text {деф }}=210,3+6,78 X_{1}-1,45 X_{2}+5,15 X_{3}+1,8 X_{1}^{2}-1,5 X_{2}^{2}+2,72 X_{3}^{2}-5,97 X_{1} X_{2}+3,24 X_{1} X_{3}+4,63 X_{2} X_{3} ;
$$

- для второй ступени размола

$Y_{6}^{p a \phi}=274,4+2,16 X_{1}-1,66 X_{2}+1,41 X_{3}+2,18 X_{1}^{2}-1,96 X_{2}^{2}+4,15 X_{3}^{2}-2,02 X_{1} X_{2}-1,325 X_{1} X_{3}+2,55 X_{2} X_{3}$.

Выборочный анализ уравнения (1) показал следующее. Влияние всех факторов на отклик является квадратичным, так как присутствуют соответствующие квадратичные члены. При этом можно утверждать, что максимальное влияние на отклик оказывает фактор $X_{1}$, соответствующий износу сегментов размалывающей гарнитуры, так как именно для этого фактора $\partial_{1 \max }=19,59$. Однако при увеличении значений фактора $X_{1}$ отклик не всегда возрастает, иногда характер влияния меняется на противоположный. Оказывают влияние парные взаимодействия факторов.

Наглядное представление об эффекте парного взаимодействия даст анализ семейства графических зависимостей $Y^{\text {деф }}$ от $X_{1}$ при различных значения $X_{3}$ и фиксированном уровне фактора $X_{2}$. Подставив значения $X_{2} .=X_{3}=+1$ в уравнение (1), получим

$$
Y_{6}^{\text {деф }}=219,85+4,05 X_{1}+1,8 X_{1}^{2} .
$$

Так как $b_{11}=1,8>0$, то уравнение описывает вогнутую функцию, то есть ветви параболы направлены вверх. Кроме того, $\left|b_{1}\right|=4,05>2\left|b_{11}\right|=3,6$, следовательно, вершина параболы находится вне диапазона варьирования фактора, а уравнение (3) описывает монотонно возрастающую функцию.

Для приближенного построения параболы воспользуемся пятью точками:

$X_{I}=-1, Y=217,6 ; X_{I}=-0,5, Y=218,275 ; X_{I}=0, Y=219,85 ; X=0,5, Y=223,32 ; X_{I}=1, Y=225,7$ (верхняя кривая на рис. 1).

Сохранив значение $X_{2}=+1$, положим теперь в уравнении (1) $X_{3}=-1$. Получим зависимость

$$
Y_{6}^{\text {ded }}=200,29-2,46 X_{I}+1,8 X_{1}^{2} .
$$

По сравнению с уравнением (3) здесь изменился не только свободный член, но и коэффициент $\mathrm{b}_{1}$, который вместо значения 4,05 принял значение $-2,46$. Это произошло из-за парного взаимодействия $\mathrm{b}_{13}$. В результате парабола, описываемая уравнением (4), становится монотонно убывающей с экстремумом вне диапазона варьирования. Это означает, что с увеличением фактора $X_{3}$, соответствующего скорости вращения нижнего шнека дефибратора, влияние износа сегментов (фактор $X_{1}$ ) на удельный расход электроэнергии увеличилось. В то же время значения удельного расхода электроэнергии возросли. Это следует из увеличения свободного члена в уравнении (3) по сравнению с (4) (нижняя кривая на рис. 1). 


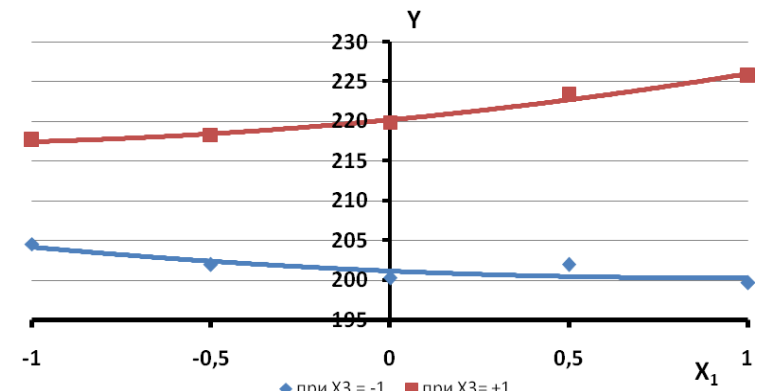

Рис. 1. Графики зависимостей $Y_{5}^{\text {деф }}=f\left(X_{l}\right)$

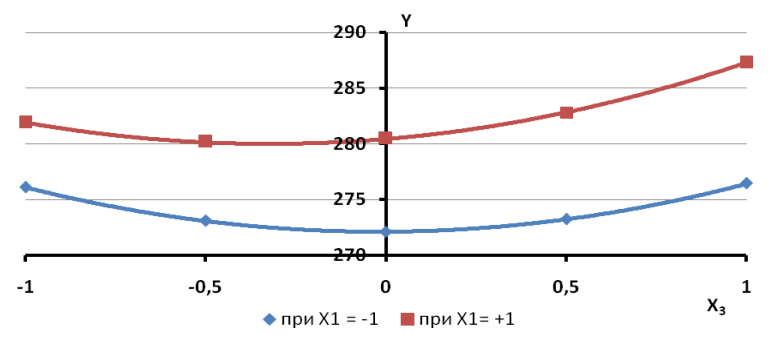

Рис. 2. Графики зависимостей $Y^{\text {раф }}=f\left(X_{3}\right)$

Аналогично можно проанализировать влияние остальных факторов и их парных взаимодействий на отклик.

Анализ уравнения (2) показал следующее. Зависимость Ү от каждого фактора является квадратичной, так как в уравнении (2) присутствуют соответствующие коэффициенты. Максимальное влияние на отклик оказывает фактор $X_{3}$, соответствующий концентрации массы в рафинаторе, так как $\partial_{3 \max }=13,59$. Также можно утверждать, что с ростом факторов $X_{1}$ и $X_{3}$ значения удельного расхода электроэнергии возрастают, а увеличение фактора $X_{2}$ позволяет снизить величину отклика.

Оценим влияние парных взаимодействий при помощи графических зависимостей. Подставив значения $X_{1}=X_{2}=-1$ в уравнение (2), получим

$$
Y_{6}^{\text {ded }}=272,1+0,185 X_{3}+4,15 X_{1}^{2} .
$$

Очевидно, что уравнение (5) описывает вогнутую функцию - $b_{33}>0$, соотношение $\left|b_{1}\right|=0,185>2\left|b_{11}\right|=8,3$ позволяет сделать вывод о том, что экстремум функции (в данном случае минимум) находится в диапазоне варьирования. Для построения графика воспользуемся точками $X_{I}=-1, Y=276,1$; $X_{l}=-0,5, Y=273,1 ; X_{l}=0, Y=272,1 ; X=0,5, Y=273,23 ; X_{I}=1, Y=276,44$ (нижняя кривая на рис. 2).

Оставив значение $X_{2}=-1$, примем $X_{1}=+1$, получим

$$
\mathrm{Y}_{6}^{\mathrm{pa \phi}}=280,46+2,635 X_{3}+4,15 X_{l}^{2} .
$$

Сравнивая уравнения (5) и (6), мы можем видеть, что значение свободного члена и коэффициента $b_{3}$ увеличилось, парабола, описываемая уравнением (6), будет более крутой, экстремум функции сместится влево, к нижней границе интервала варьирования. Таким образом проявилось влияние парного взаимодействия $b_{13}$. Это означает, что с увеличением износа режущей гарнитуры влияние концентрации массы в рафинаторе на удельный расход электроэнергии увеличивается (верхняя кривая на рис. 2).

Анализируя графические зависимости на рисунке 2, можно сделать следующие выводы. С ростом значений концентрации увеличивается удельный расход электроэнергии. При этом на начальной стадии обработки древесного волокна влияние увеличения концентрации приводит к незначительному снижению значений удельного расхода электроэнергии, затем значения отклика возрастают по мере возрастания фактора износа сегментов. Так проявляется парное взаимодействие факторов $X_{1} X_{3}$ и их влияние на величину удельного расхода электроэнергии.

Задача по определению оптимальных условий проведения процесса размола при производстве трудновоспламеняемых древесноволокнистых плит мокрым способом для размола щепы была решена в следующем виде:

$$
\begin{aligned}
& \mathrm{f}=E_{y d}{ }^{\partial e \phi}\left(L / h, z, n, \omega_{6}\right) \rightarrow \min \\
& \int \Delta m>60 \% \text {. } \\
& \tau>4 \text { мин; } \\
& \sigma_{\text {изг }}>33 \mathrm{MПа;} \\
& A<13 \% \\
& h \geq 2,5 \mathrm{MM} \text {; } \\
& 10 \% \leq L / h \leq 90 \% \text {; } \\
& 0,05 \mathrm{MM} \leq z \leq 0,15 \mathrm{MM} \text {; } \\
& 12 \text { об/мин } \leq n \leq 15,4 \text { об/мин; } \\
& 10 \% \leq \omega_{B} \leq 50 \% \text {. }
\end{aligned}
$$


В результате были определены оптимальные значения варьируемых переменных для процесса размола щепы:

- износ сегментов размалывающей гарнитуры $L / h=50 \%$;

- зазор между дисками дефибратора $z=0,1$ мм;

- скорость вращения нижнего шнека $n=12$ об/мин;

- массовая доля вермикулита в древесноволокнистой композиции $\omega_{6}=30 \%$.

Подставив найденные значения входных факторов в полученные ранее уравнения, получили соответствующие значения исследуемых параметров при размоле щепы:

- потеря массы образца $\Delta m=68,7 \%$;

- время достижения максимальной температуры газообразных продуктов горения $\tau=4,8$ мин;

- предел прочности при изгибе $\sigma_{\text {изг }}=35,21 \mathrm{MПа;}$

- водопоглощение лицевой стороной за 24 ч $A=12,15 \%$;

- толщина $h=2,7$ мм;

- удельный расход электроэнергии $E_{y d}$ деф $=199,9$ кВт·ч/т.

Задача по определению оптимальных условий проведения процесса размола при производстве трудновоспламеняемых древесноволокнистых плит мокрым способом для размола древесноволокнистой массы была решена в виде:

$\mathrm{f}=E_{y d}{ }^{p a \phi}\left(L / h, z, n, \omega_{6}\right) \rightarrow \min$

$(\Delta m>60 \%$

$\tau>4$ мин;

$\sigma_{\text {изг }}>33 \mathrm{MПа;}$

$A<13 \%$;

$h \geq 2,5 \mathrm{MM}$;

$10 \% \leq L / h \leq 90 \%$;

$0,05 \mathrm{MM} \leq z \leq 0,15 \mathrm{MM}$

$2,5 \% \leq c \leq 3,5 \%$

$10 \% \leq \omega_{6} \leq 50 \%$.

Для размола древесноволокнистой массы были определены оптимальные значения варьируемых переменных:

- износ сегментов размалывающей гарнитуры $L / h=50 \%$;

- зазор между дисками рафинатора $z=0,1$ мм;

- концентрация массы в бассейне перед рафинатором $c=3 \%$;

- массовая доля вермикулита в древесноволокнистой композиции $\omega_{6}=30 \%$.

Подставив найденные значения входных факторов в полученные ранее уравнения, получили соответствующие значения исследуемых параметров при размоле щепы:

- потеря массы образца $\Delta m=65,9 \%$;

- время достижения максимальной температуры газообразных продуктов горения $\tau=5,0$ мин;

- предел прочности при изгибе $\sigma_{\text {изг }}=37,8 \mathrm{MПа;}$

- водопоглощение лицевой стороной за 24 ч $A=11,8 \%$;

- толщина $h=2,8$ мм;

- удельный расход электроэнергии $E_{y \partial}{ }^{p a \phi}=279,9$ кВт·ч/т.

Испытания на физико-механические характеристики и параметры пожарной опасности ДВП, изготовленных из древесноволокнистой массы, полученной при оптимальных условиях, показали следующие результаты:

- предел прочности при изгибе $\sigma_{u з 2}=41$ МПа;

- водопоглощение лицевой стороной за 24 ч $S=11 \%$;

- толщина $b=2,7$ мм;

- потеря массы образца $\Delta m=65 \%$;

- время достижения максимальной температуры газообразных продуктов горения $\tau=5,0$ мин.

\section{Выводы}

Таким образом, полученные в ходе исследования зависимости позволяют, варьируя конструктивными параметрами размалывающих машин и технологическими характеристиками процесса размола древес- 
новолокнистой массы, не только получить древесноволокнистые плиты с заданными свойствами, но и сократить расход электроэнергии на производство в среднем на 7\%.

Экономический эффект от применения оптимальных режимов размола равен экономии условнопостоянной части расходов в себестоимости за счет снижения удельного расхода электроэнергии и затрат на сырье, прибыли предприятия за счет улучшения качества готовых древесноволокнистых плит и составит около 2,5 млн руб. в год. Прирост прибыли от применения оптимальных режимов размола при выпуске 1 млн м² трудновоспламеняемых ДВП составит около 1 млн руб. ежегодно.

\section{Список литературы}

1. Антонов А.В., Петрушева Н.А., Алашкевич Ю.Д. Получение огнезащищенных древесноволокнистых плит // Лесной журнал. 2012. №4. С. 99-104.

2. Антонов А.В., Петрушева Н.А., Алашкевич Ю.Д., Чижов А.П. Обоснование использования вермикулита в производстве ДВП со специальными свойствами // Новые достижения в химии и химической технологии растительного сырья: сб. материалов V Всерос. конф. с междунар. участием. Барнаул, 2012. С. 429-432.

3. Антонов А.В., Петрушева Н.А., Алашкевич Ю.Д., Чижов А.П. Математическая модель получения ДВП со специальными свойствами // Новые достижения в химии и химической технологии растительного сырья: сб. материалов V Всерос. конф. с междунар. участием. Барнаул, 2012. С. 427-429.

4. Антонов А.В., Петрушева Н.А., Алашкевич Ю.Д., Чижов А.П. Влияние технологических и конструктивных параметров размола на свойства трудновоспламеняемых древесноволокнистых плит // Химия растительного сырья. 2012. №4. С. 221-225.

5. Антонов А.В., Петрушева Н.А., Алашкевич Ю.Д., Чижов А.П. Размол древесноволокнистых полуфабрикатов при производстве трудновоспламеняемых древесноволокнистых плит // Химия растительного сырья. 2012. №4. C. 215-219.

6. Пижурин А.А., Пижурин А.Н. Моделирование и оптимизация процессов деревообработки. М., 2004.375 с.

7. Пижурин А.Н., Розенблит М.С. Исследование процессов деревообработки. М., 1984. 200 с.

8. Боровиков В.П., Боровиков И.П. STATISTICA. Статистический анализ и обработка данных в среде Windows. M., $1998.605 \mathrm{c}$.

9. Ребрин С.П., Мерсов Е.Д., Евдокимов Е.Д. Технология ДВП. М., 1982. 272 с.

10. Антонов А.В., Петрушева Н.А., Чижов А.П., Ярошенко К.О., Мухамедшина Л.М. Использование вермикулита в производстве древесноволокнистых плит // Молодые ученые в решении актуальных проблем науки: сб. ст. по материалам всерос. науч.-практ. конф. с междунар. участием. Красноярск, 2011. Т. 2. С. $62-64$.

11. Антонов А.В., Алашкевич Ю.Д., Петрушева Н.А., Чижов А.П. Обоснование использования вермикулита в производстве ДВП со специальными свойствами // Новые достижения в химии и химической технологии растительного сырья: сб. материалов V Всерос. конф. с междунар. участием. Барнаул, 2012. С. 429-432.

Поступило в редакиию 21 января 2016 г.

После переработки 3 октября 2016 г. 
Antonov A.V. ${ }^{1 *}$, Petrusheva N.A. ${ }^{2}$, Alashkevich Y.D. ${ }^{1,3}$, Reshetova N.S. ${ }^{3}$ THE SEARCH OF OPTIMAL TECHNOLOGICAL MODES IN THE PRODUCTION OF FLAME-RESISTANT FIBREBOARD

${ }^{I}$ Siberian Fire and Rescue Academy of FMS MOE Russia, ul. Severnaya, 1, Zheleznogorsk, Krasnoyarsk region, 662972 (Russia), e-mail: antonov012@mail.ru

${ }^{2}$ Lesosibirskiy branch of the Siberian State Technological University, ul. Pobedy, 29, Lesosibirsk, 662543 (Russia)

${ }^{3}$ Siberian State Technological University, pr. Mira, 82, Krasnoyarsk 660049 (Russia)

The paper presents the results of solving the problem of finding the optimal modes of grinding process in the manufacture of flame retardant hardboard to minimize energy consumption. The regression model of the second order, resulting from the implementation of a multifactorial experimental studies are presented and described in the previously published works provides a wealth of information on the influence of varying factors on output values. These models can be used to optimize conditions for the functioning of the object. Effective method of finding optimal conditions of operation of the facility, the regression equation of the second order method is quasi-Newton. The task of determining the optimum conditions of the grinding process in the manufacture of fire-resistant fiberboard wet method for grinding of wood chips was solved in two stages. The first stage was established the dependence of specific energy consumption from technological and constructive factors of the grinding process in the manufacture of flame retardant hardboard. In the second phase were identified following technological features of the grinding process wood fiber mass and design parameters of the grinding machines, where the value of the specific energy consumption was minimal. The solution of the problem will allow, by varying the design parameters of the grinding machines and technological characteristics of the process of grinding wood pulp, not only to obtain a wood-fiber plate with the desired properties, but also to reduce the consumption of electricity for production of an average of $7 \%$. The economic effect from the use of optimum modes of grinding is equal to savings of conditionally constant part of the costs in the cost by reducing specific energy consumption and raw material costs, the profits of the enterprise by improving the quality of the finished fibreboard.

Keywords: fiberboard, fire danger, the mathematical description of the object-functioning, optimal conditions.

\section{References}

1. Antonov A.V., Petrusheva N.A., Alashkevich Ju.D. Lesnoj zhurnal, 2012, no. 4, pp. 99-104. (in Russ.).

2. Antonov A.V., Petrusheva N.A., Alashkevich Ju.D., Chizhov A.P. Novye dostizhenija v himii $i$ himicheskoj tehnologii rastitel'nogo syr'ja: sb. materialov V Vseros. konf. s mezhdunar. uchastiem. [New advances in chemistry and chemical technology of vegetable raw materials: a collection of the V All-Russian conference with international participation]. Barnaul, 2012, pp. 429-432. (in Russ.).

3. Antonov A.V., Petrusheva N.A., Alashkevich Ju.D., Chizhov A.P. Novye dostizhenija v himii $i$ himicheskoj tehnologii ras-titel'nogo syr'ja: sb. materialov V Vseros. konf. s mezhdunar. uchastiem. [New advances in chemistry and chemical technology of vegetable raw materials: a collection of the $\mathrm{V}$ All-Russian conference with international participation]. Barnaul, 2012, pp. 427-429. (in Russ.).

4. Antonov A.V., Petrusheva N.A., Alashkevich Iu.D., Chizhov A.P. Khimiia rastitel'nogo syr'ia, 2012, no. 4, pp. 221-225. (in Russ.).

5. Antonov A.V., Petrusheva N.A., Alashkevich Iu.D., Chizhov A.P. Khimiia rastitel'nogo syr'ia, 2012, no. 4, pp. 215-219. (in Russ.).

6. Pizhurin A.A., Pizhurin A.N. Modelirovanie i optimizatsiia protsessov derevoobrabotki. [Modelling and optimization of woodworking processes]. Moscow, 2004, 375 p. (in Russ.).

7. Pizhurin A.N., Rozenblit M.S. Issledovanie protsessov derevoobrabotki. [Woodworking processes Research]. Moscow, 1984, 200 p. (in Russ.).

8. Borovikov V.P., Borovikov I.P. STATISTICA. Statisticheskii analiz i obrabotka dannykh v srede Windows. [STATISTICA. Statistical analysis and data processing in a Windows environment]. Moscow, 1998, 605 p. (in Russ.).

9. Rebrin S.P., Mersov E.D., Evdokimov E.D. Tekhnologiia DVP. [Technology fiberboard]. Moscow, 1982, 272 p. (in Russ.).

10. Antonov A.V., Petrusheva N.A., Chizhov A.P., Iaroshenko K.O., Mukhamedshina L.M. Molodye uchenye v reshenii aktual'nykh problem nauki: sb. st. po materialam vseros. nauch.-prakt. konf. s mezhdunar. uchastiem. [Young scientists in solving urgent problems of science: a collection of articles based on the All-Russian scientific-practical conference with international participation]. Krasnoyarsk, 2011, vol. 2, pp. 62-64. (in Russ.).

11. Antonov A.V., Alashkevich Iu.D., Petrusheva N.A., Chizhov A.P. Novye dostizhenija v himii $i$ himicheskoj tehnologii ras-titel'nogo syr'ja: sb. materialov V Vseros. konf. s mezhdunar. uchastiem. [New advances in chemistry and chemical technology of vegetable raw materials: a collection of the V All-Russian conference with international participation]. Barnaul, 2012, pp. 429-432. (in Russ.).

Received January 21, 2016

Revised October 3, 2016

\footnotetext{
* Corresponding author.
} 

